\title{
Urine D-dimer Level in Severe Preeclampsia-complicated Acute Kidney Injury: A Cross-sectional Study
}

\author{
Putri Mirani ${ }^{1}$, Noroyono Wibowo ${ }^{2}$
}

\begin{abstract}
Introduction: Preeclampsia has become the most common glomerular-based kidney disease affecting up to $8 \%$ of normal pregnancies. ${ }^{1-3}$ Thus, a worsening condition of preeclampsia will be related to an increasing risk of renal disease, particularly acute kidney injury (AKI). ${ }^{1,2}$ Acute kidney injury has become the common renal disease complication due to severe preeclampsia with the incidence up to $5 \% .{ }^{4}$ This complication is mainly caused by thrombotic microangiopathy involving renal arteries, which can be observed with an increasing urine $\mathrm{D}$-dimer level. This study aims to determine the urine D-dimer level in severe preeclampsia-complicated AKI.

Materials and methods: A cross-sectional study was conducted in Obstetric Emergency Unit and Obstetric Ward Unit, Cipto Mangunkusumo General Hospital, from January to April, 2013. Subjects were divided into two groups: severe preeclampsia-complicated AKI and normotensive pregnancy. The main outcome of this study was that urine D-dimer level was based on the cutoff point from receiver operating characteristic (ROC). The secondary outcomes were its sensitivity and specificity. Statistical analysis was performed using Mann-Whitney and Spearman correlation tests. Data were analyzed using SPSS 20.0.

Results: There were 65 subjects collected during the study and divided into two groups: 35 patients with severe preeclampsia-complicated AKI and 30 patients with normotensive pregnancy. There was a significant increase in the urine D-dimer level in patients with severe preeclampsiacomplicated AKI compared with patients with normotensive pregnancy $(2503 \mathrm{ng} / \mathrm{mL}$ vs $236.2 \mathrm{ng} / \mathrm{mL} ; p=0.001)$. Based on the ROC, the cutoff point for the urine D-dimer level was $>818 \mathrm{ng} / \mathrm{dL}$ with area under the ROC curve was $0.819(81.9 \%)$, sensitivity $80 \%$, and specificity $73 \%$.

Conclusion: The urine D-dimer level significantly increased in severe preeclampsia-complicated AKI with a cutoff point of $>818 \mathrm{ng} / \mathrm{dL}$, sensitivity $80 \%$, and specificity $73 \%$.

Keywords: Acute kidney injury, Severe preeclampsia, Urine D-dimer.

Journal of South Asian Federation of Obstetrics and Gynaecology (2019): 10.5005/jp-journals-10006-1720
\end{abstract}

\section{INTRODUCTION}

Hypertensive complication during pregnancy remains a major problem increasing maternal-neonatal mortality and morbidity, particularly manifest as preeclampsia. ${ }^{1,2,5,6}$ It has become the most common glomerular-based kidney disease affecting up to $8 \%$ of normal pregnancies. ${ }^{1-3}$ Thus, a worsening condition of preeclampsia is related to an increasing risk of renal disease, particularly acute kidney injury $(\mathrm{AKI}){ }^{1,2}$

Acute kidney injury has become the common renal disease complication due to severe preeclampsia with the incidence up to $5 \% .{ }^{4}$ This complication is mainly caused by thrombotic microangiopathy involving renal arteries. ${ }^{1,3,6}$ It began as an imbalance process of the coagulation system between prostacyclin and thromboxane, thus resulting in the circulation of thrombin in the blood vessels. ${ }^{7,8}$ As the coagulation process continues, the circulating thrombin disintegrated and released fibrin degradation products, including $\mathrm{D}$-dimer, thereby increasing the $\mathrm{D}$-dimer level. ${ }^{6-8}$

Severity of thrombotic microangiopathy involving renal arteries due to worsening preeclampsia can be observed clinically as AKI and biochemically as increasing urine D-dimer level. This study aims to determine the urine $D$-dimer level in severe preeclampsia complicated with AKI.

\section{Materials and Methods}

This was a cross-sectional study conducted in Obstetric Emergency Unit and Obstetric Ward Unit, Cipto Mangunkusumo General Hospital, from January to April 2013. Subjects were divided into two

\footnotetext{
1,2Department of Obstetrics and Gynecology, Universitas Indonesia Cipto Mangunkusumo Hospital, Central Jakarta, Indonesia
}

Corresponding Author: Noroyono Wibowo, Department of Obstetrics and Gynecology, Universitas Indonesia - Cipto Mangunkusumo Hospital, Central Jakarta, Indonesia, Phone: +62 2131924404, e-mail: norowibowo@gmail.com

How to cite this article: Mirani P, Wibowo N. Urine D-dimer Level in Severe Preeclampsia-complicated Acute Kidney Injury: A Cross-sectional Study. J South Asian Feder Obst Gynae 2019;11(5): 315-317.

Source of support: Nil

Conflict of interest: None

groups: severe preeclampsia-complicated AKI and normotensive pregnancy. Inclusion criteria for the severe preeclampsia group were singleton live intrauterine pregnancy, gestational age $>20$ weeks, diagnosed as severe preeclampsia/eclampsia with/ without HELLP syndrome-complicated AKI, and normal body temperature. Inclusion criteria for the control group were singleton live intrauterine pregnancy, gestational age $>20$ weeks, normotensive, and normal body temperature. Exclusion criteria for both groups were having history of liver disease, having history of hematology and coagulation disorder, having history of renal disease previously, was using anticoagulant and thrombolytic agents for treatment, diagnosed as disseminated intravascular coagulation, unwilling to participate in study, and sample damage. This is a pilot study, therefore used a minimal sample size of 30 subjects for each group. 
Table 1: Subject characteristic in urine D-dimer level in severe preeclampsia-complicated AKI study

\begin{tabular}{lll}
\hline & Severe preeclampsia-complicated & \\
Subject characteristics & AKI $(n=35)$ & Normotensive pregnancy $(n=30)$ \\
\hline Age (years) & $30 \pm 5$ & $28 \pm 5$ \\
Gestational age (weeks) & $32(23-40)$ & $36(23-41)$ \\
Primiparity $(\%)$ & $13(37.1)$ & $14(50)$ \\
Systolic blood pressure $(\mathrm{mm} \mathrm{Hg})$ & $170(160-240)$ & $120(100-130)$ \\
Diastolic blood pressure $(\mathrm{mm} \mathrm{Hg})$ & $103(100-140)$ & $75(60-90)$ \\
Temperature $\left({ }^{\circ} \mathrm{C}\right)$ & $36.6(36-37)$ & $36.6(36.4-36.8)$ \\
Diuresis $(\mathrm{mL} / \mathrm{kg}$ body weight/hour) & $0.3 \pm 0.08$ & $1.54 \pm 0.30$ \\
Urine creatinine $(\mathrm{mg} / \mathrm{dL})$ & $73.7(10.4-203.4)$ & $51.5(37-51.6)$ \\
Plasma creatinine $(\mathrm{mg} / \mathrm{dL})$ & $1.7 \pm 1.8$ & $0.7(0.5-0.8)$ \\
Leukocyte $\left.(/ \mathrm{mm})^{3}\right)$ & $18,717 \pm 8555.2$ & $9,050(6,660-14,600)$ \\
Plasma D-dimer $(\mathrm{ng} / \mathrm{mL})$ & $2,472 \pm 1,385$ & $2,525 \pm 1,607$ \\
Urine D-dimer $(\mathrm{ng} / \mathrm{mL})$ & $2,503(106-4,290)$ & $788 \pm 1,179$ \\
\hline
\end{tabular}

Table 2: Mode of delivery and neonatal outcome between two groups

\begin{tabular}{llll}
\hline Neonatal outcome & $\begin{array}{l}\text { Severe preeclampsia- } \\
\text { complicated AKI }(n=35)\end{array}$ & $\begin{array}{l}\text { Normotensive } \\
\text { pregnancy }(n=30)\end{array}$ & $p$ \\
\hline Mode of delivery & & & \\
Spontaneous $[n(\%)]$ & $16(30.1)$ & $14(46.6)$ & $>0.05^{*}$ \\
Cesarean section $[n(\%)]$ & $19(54.9)$ & $16(53.3)$ & \\
Birth weight (g) [median (min-max)] & $1,970(600-3,265)$ & $2,665(600-4,000)$ & $0.03^{\dagger}$ \\
Apgar score minute 1 [median (min-max)] & $7(1-9)$ & $9(1-9)$ & $0.03^{\dagger}$ \\
\hline
\end{tabular}

${ }^{*}$ Chi-square test

${ }^{\dagger}$ Mann-Whitney test

The main outcome of this study was that urine D-dimer level was based on the cutoff point from receiver operating characteristic (ROC). The secondary outcomes were sensitivity and specificity. Statistical analysis was performed using Mann-Whitney and Spearman correlation tests. Data were analyzed using SPSS 20.0. This study had been approved by the Ethical Committee Faculty of Medicine University of Indonesia/RSCM with ethical approval no. 746/H2.F1/ETIK/2012.

\section{Results}

There were 65 subjects collected during study and divided into two groups: 35 patients with severe preeclampsia-complicated AKI and 30 patients with normotensive pregnancy. All subject characteristics are shown in Table 1.

Table 2 shows the mode of delivery and neonatal outcome between two group studies. There was no significant difference in the mode of delivery, but there was a significant difference in the neonatal outcome. Neonatal delivered from severe preeclampsiacomplicated AKI group were smaller in weight (median $1970 \mathrm{~g}$ ) and were having mild asphyxia (media Apgar score 7).

There was a significant increase in the urine D-dimer level in patients with severe preeclampsia-complicated AKI compared with patients with normotensive pregnancy $(2503 \mathrm{ng} / \mathrm{mL}$ vs $236.2 \mathrm{ng} / \mathrm{mL} ; p=0.001$ ). Based on the ROC, the cutoff point for the urine D-dimer level was $>818 \mathrm{ng} / \mathrm{dL}$ with area under the ROC curve (AUC) was 0.819 (81.9\%), sensitivity $80 \%$, and specificity $73 \%$. receiver operating characteristic with the cutoff point from AUC is shown in Figure 1.

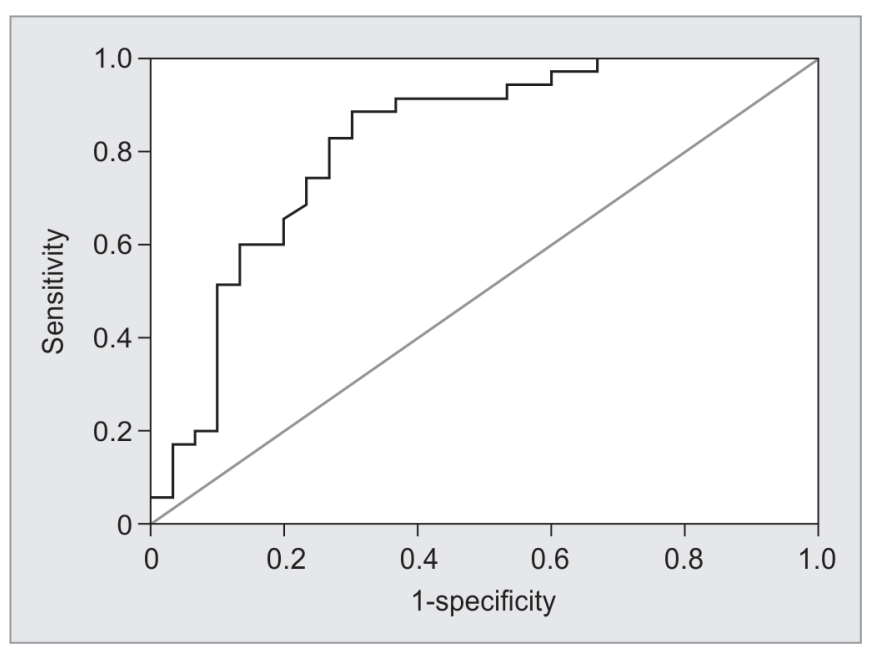

Fig. 1: Receiver operating characteristic of the urine D-dimer level in severe preeclampsia-complicated acute kidney injury (AKI)

\section{Discussion}

Preeclampsia has become the most common hypertensive complication during pregnancy risking not only cardiovascular system but also renal function. ${ }^{2,5,6}$ Thus, the worsening condition of preeclampsia should be detected accurately and managed carefully. Based on the subject characteristic, subjects in the severe preeclampsia-complicated AKI group were significantly different from normotensive groups, especially in blood pressure, diuresis, 
urine, and plasma creatinine level. Blood pressure and creatinine level (both urine and plasma) were significantly higher, whereas diuresis in severe preeclampsia-complicated AKI was significantly lower. Hypertensive characteristic in this study corresponds to American College of Obstetricians and Gynecologists (ACOG) criteria for severe preeclampsia, while diuresis and creatinine level correspond to risk, injury, failure, loss of kidney function, and endstage kidney disease (RIFLE) and acute kidney injury network (AKIN) criteria for AKI. ${ }^{6,9-12}$

In this study, the urine D-dimer level was significantly higher in severe preeclampsia-complicated AKI compare with normotensive group ( $2503 \mathrm{ng} / \mathrm{mL}$ vs $236.2 \mathrm{ng} / \mathrm{mL} ; p=0.001)$. This condition was related to fibrin accumulation in glomerular endothelial cells causing vascular permeability disruption, thus increasing D-dimer excretion through urinary process. Therefore, increased urine D-dimer level can be used as diagnostic tools for diagnosis of severity of worsening preeclampsia, particularly severe preeclampsia-complicated AKI.,13 Other condition related to severity of preeclampsia was clinical symptoms of oliguria found in the severe preeclampsia-complicated AKI group. This was showing severe glomerular endothelial disruption leading to $\mathrm{AKI}^{2,3,6}$

Based on the ROC, the cutoff point from AUC for urine D-dimer level was 0.819 (81.9\%), with sensitivity $80 \%$ and specificity $73 \%$. This value can be used as noninvasive diagnostic tools (AUC > 80\%) and can predict the worsening condition in severe preeclampsiacomplicated AKI.

This study was a prior study. There were some limitations regarding sample size being used in this study. Thus, we recalculated the power of study to minimal mean level of urine D-dimer difference and standard deviation, which resulted in $\beta$-value 1.3 that corresponds to power of $90-95 \%$. It was shown that sample size being used in this study was qualified enough to compare urine D-dimer level between two groups. Further study should be conducted to generalize the cutoff point in large population, so that it can be compared with renal biopsy as a gold standard for diagnosing thrombotic microangiopathy due to preeclampsia and to identify other factors causing AKI besides endothelial disruption due to fibrin accumulation on glomerular endothelial cells.

\section{Conclusion}

The urine D-dimer level significantly increased in severe preeclampsia-complicated AKI, with the cutoff point of $>818 \mathrm{ng} / \mathrm{dL}$, sensitivity $80 \%$, and specificity $73 \%$.

\section{References}

1. Cornelis $\mathrm{T}$, Odutayo A, Keunen J, et al. The kidney in normal pregnancy and preeclampsia. Semin Nephrol 2011;31(1):4-14. DOI: 10.1016/ j.semnephrol.2010.10.002.

2. Eiland E, Nzerue C, Faulkner M. Preeclampsia 2012. J Pregnancy 2012;2012:586578. DOI: 10.1155/2012/586578.

3. Stillman IE, Karumanchi SA. The glomerular injury of preeclampsia. J Am Soc Nephrol 2007;18(8):2281-2284. DOI: 10.1681/ASN.2007020255.

4. Machado S, Figueiredo N, Borges $A$, et al. Acute kidney injury in pregnancy: a clinical challenge. J Nephrol 2012;25(1):19-30. DOI: 10.5301/jn.5000013.

5. Abraham KA, Kennelly M, Dorman AM, et al. Pathogenesis of acute renal failure associated with the HELLP syndrome: a case report and review of the literature. Eur J Obstet Gynecol Reprod Biol 2003;108(1):99-102. DOI: 10.1016/S0301-2115(02)00352-4.

6. Fakhouri F, Vercel C, Fremeaux-Bacchi V. Obstetric nephrology: AKI and thrombotic microangiopathies in pregnancy. Clin J Am Soc Nephrol 2012;7(12):2100-2106. DOI: 10.2215/CJN.13121211.

7. Friedman SA, Schiff E, Emeis JJ, et al. Biochemical corroboration of endothelial involvement in severe preeclampsia. Am J Obstet Gynecol 1995;172(1 Pt 1):202-203. DOI: 10.1016/0002-9378(95)90113-2.

8. Taylor RN, de Groot CJ, Cho YK, et al. Circulating factors as markers and mediators of endothelial cell dysfunction in preeclampsia. Semin Reprod Endocrinol 1998;16(1):17-31. DOI: 10.1055/s-2007-1016249.

9. Ganesan C, Maynard SE. Acute kidney injury in pregnancy: the thrombotic microangiopathies. J Nephrol 2011;24(5):554-563. DOI: 10.5301/JN.2011.6250.

10. Lameire N, Van Biesen W, Vanholder R. Acute renal failure. Lancet 2005;365(9457):417-430. DOI: 10.1016/S0140-6736(05)70238-5.

11. ACOG. Diagnosis and management of pre-eclampsia and eclampsia. ACOG Practice Bulletin 2002;33:1-9.

12. AOA. Challenges in diagnosis and treatment of acute kidney injury in pregnancy. Nephro Urol Mon 2012;4:340-344.

13. Trofatter Jr KF, Trofatter MO, Caudle MR, et al. Detection of fibrin D-dimer in plasma and urine of pregnant women using dimer test latex assay. South Med J 1993;86(9):1017-1021. DOI: 10.1097/00007611199309000-00009. 